\title{
Size-controlled green synthesis of silver nanoparticles mediated by gum ghatti (Anogeissus latifolia) and its biological activity
}

\author{
Aruna Jyothi Kora', Sashidhar Rao Beedu ${ }^{2 *}$ and Arunachalam Jayaraman ${ }^{1}$
}

\begin{abstract}
Background: Gum ghatti is a proteinaceous edible, exudate tree gum of India and is also used in traditional medicine. A facile and ecofriendly green method has been developed for the synthesis of silver nanoparticles from silver nitrate using gum ghatti (Anogeissus latifolia) as a reducing and stabilizing agent. The influence of concentration of gum and reaction time on the synthesis of nanoparticles was studied. UV-visible spectroscopy, transmission electron microscopy and X-ray diffraction analytical techniques were used to characterize the synthesized nanoparticles.

Results: By optimizing the reaction conditions, we could achieve nearly monodispersed and size controlled spherical nanoparticles of around $5.7 \pm 0.2 \mathrm{~nm}$. A possible mechanism involved in the reduction and stabilization of nanoparticles has been investigated using Fourier transform infrared spectroscopy and Raman spectroscopy.

Conclusions: The synthesized silver nanoparticles had significant antibacterial action on both the Gram classes of bacteria. As the silver nanoparticles are encapsulated with functional group rich gum, they can be easily integrated for various biological applications.
\end{abstract}

Keywords: Antibacterial, Autoclaving, Gum ghatti, Silver nanoparticles, Surface-Enhanced Raman Scattering (SERS)

\section{Background}

A survey of earlier literature suggests that various natural polymers such as starch [1], chitosan [2], and tannic acid [3] have been reported as reducing agents for the synthesis of silver and gold nanoparticles. It has been demonstrated that the plant-based exudate gums such as gum Acacia [4] and gum kondagogu [5] can be utilized as reducing and stabilizing agents for the silver nanoparticle biosynthesis. Gum gellan, a microbial heteropolysaccharide, was employed for similar purpose in the case of gold nanoparticles [6]. Gum ghatti is a naturally occurring water soluble, complex polysaccharide derived as an exudate from the bark of Anogeissus latifolia (Combretaceae family), a native tree of the Indian sub-continent. The name gum ghatti has originated from its transportation through mountain passes or ghats. This native Indian gum is collected from the forests by the tribals and

\footnotetext{
* Correspondence: sashi_rao@yahoo.com

${ }^{2}$ Department of Biochemistry, University College of Science, Osmania

University, Hyderabad 500 007, AP, India

Full list of author information is available at the end of the article
}

marketed through government organizations such as Girijan Co-operative Corporation Ltd., Visakhapatnam, India. The world production of gum ghatti is about $1,000-1,500 \mathrm{MT} /$ year $[7,8]$. This biopolymer is an arabinogalactan type of natural gum and its morphological, structural, physico-chemical, compositional, solution, thermal, rheological, and emulsifying properties have been well documented and studied [9-17]. This biopolymer is a high-arabinose, protein rich, acidic heteropolysaccharide, occurring in nature as mixed calcium, magnesium, potassium, and sodium salt $[12-14,16]$. The primary structure of this gum is composed of sugars such as, L-arabinose, D-galactose, D-mannose, D-xylose, and D-glucuronic acid in a molar ratio of 48:29:10:5:10 and $<1 \%$ of rhamnose, which is present as non-reducing end-groups. The gum contains alternating 4-O-substituted and 2-O-substituted $\alpha$-D-mannopyranose units and chains of $1 \rightarrow 6$ linked $\beta$-D-galactopyranose units with side chains of L-arabinofuranose residues. Six percent of rhamnose in the polysaccharide is linked to the galactose backbone as $\alpha$-Rhap- $(1 \rightarrow 4) \beta$-galactopyranose 
side chain. It has a molecular weight of $8.94 \times 10^{7} \mathrm{~g} / \mathrm{mol}$ $[12,13,15,16]$.

The gum ghatti with a CAS number 9000-28-6 is recognized as "generally recognized as safe" (GRAS) and approved as a food ingredient (Code 184.1333) by the Food and Drug Administration, USA, under the function of emulsifier and emulsifier salt. Its use in food is also approved in Japan, China, South Korea, Singapore, Russia, Australia, South Africa, Iran, Saudi Arabia, Latin America, and other countries. But, it is not approved as a food additive in European Union and not been accorded a European food safety E number. It is considered as a food grade additives of food by the Bureau of Indian Standards, India under Indian Standard IS 7239:1974 [13,15,16]. In India, the application of this hydrocolloid in traditional medicine and food preparations is well known for centuries. The gum is fed to the lactating mothers in the form of laddu to enhance the nutrients in milk as well as to prevent the post-delivery backache [18]. The gum laddu is also eaten as a heating agent during winter season $[18,19]$. The gum ghatti is comprised of around $80 \%$ soluble dietary fiber and acts a prebiotic by supplying the matrix required to sustain the bacterial flora of the human colon. This hydrocolloid is resistant to gastrointestinal enzymes and known to be degraded enzymatically only by the specific microflora of the colon such as Bifidobacterium longum, thereby aiding in bifidus fermentation [20-22]. This gum is also given for the treatment of diarrhea and diabetes [23]. Earlier studies on gum ghatti fed white leghorn cockerels and albino rats have established the hypolipidemic activity of gum ghatti $[24,25]$. Recent studies have established that gum ghatti has a potential application as a release modifier for controlled drug delivery [26]. Gum ghatti has long been used in non-food applications, such as, calico printing, explosives, varnishes, car polishes, ceramics, cosmetics; and in pharmaceutical, textile, paper, petroleum, and mining industries. Also, this biopolymer aids in various photoelectric determinations $[7,8,13,16,23]$.

The attractive features of gum ghatti prompted us to use this biopolymer for the synthesis and stabilization of silver nanoparticles due to its (i) edible nature and GRAS [13]; (ii) natural availability and low cost [23]; (iii) intermediate viscosity between gum arabic and gum karaya $[14,15]$; (iv) greater stability to $\mathrm{pH}$ acidification, electrolyte addition, and high-pressure treatment [15,17]; (v) higher emulsification ability and superior emulsion storage stability at lower concentrations [15], and (vi) exceptional interfacial characteristics with faster kinetics [17]. The green synthesis of inherently safer silver nanoparticles depends on the adoption of the basic requirements of green chemistry; the solvent medium, the benign reducing agent, and the non-hazardous stabilizing agent $[1,27]$. In this context, we have explored and developed a facile and green synthetic route for the production of silver nanoparticles using a proteinaceous, edible, renewable natural plant polymer, gum ghatti as both the reducing and stabilizing agents. Being a natural polymer, gum ghatti is amenable for biodegradation. The synthesis was carried out in aqueous medium by autoclaving, without the addition of any external chemical reducing agent. In this study, autoclaving was adopted as a synthetic route to produce sterile silver nanoparticles that are completely free from bacteria, viruses, and spores, which would suit biological applications. The focus of this study was on (i) the synthesis, (ii) characterization, and (iii) capping and stabilization of silver nanoparticles. In addition, we have also demonstrated the antibacterial activity of the prepared nanoparticles on Gram-positive and Gramnegative bacteria for finding out the potential of the generated nanoparticles for various environmental and biomedical applications.

\section{Methods}

\section{Characterization of synthesized silver nanoparticles}

In order to study the formation of silver nanoparticles, the UV-Visible absorption spectra of the prepared colloidal solutions were recorded using an Elico SL 196 spectrophotometer (Hyderabad, India), from 250 to $800 \mathrm{~nm}$, against autoclaved gum blank. The absorption spectra of gum before and after autoclaving were also recorded against ultra pure water blank. The size and shape of the nanoparticles were obtained with Hitachi $\mathrm{H}$ 7500 (Tokyo, Japan) and JEOL 3010 (Tokyo, Japan) transmission electron microscopes (TEM), operating at 80 and $200 \mathrm{kV}$, respectively. Samples were prepared by depositing a drop of colloidal solution on a carboncoated copper grid and drying at room temperature. The X-ray diffraction (XRD) analysis was conducted with a Rigaku, Ultima IV diffractometer (Tokyo, Japan) using monochromatic $\mathrm{Cu} \mathrm{K} \alpha$ radiation $(\lambda=1.5406 \AA)$ running at $40 \mathrm{kV}$ and $30 \mathrm{~mA}$. The intensity data for the nanoparticle solution deposited on a glass slide were collected over a $2 \theta$ range of $35-85^{\circ}$ with a scan rate of $1 \%$ min. The nanoparticles were recovered from the synthesized solutions by centrifugation and made into powders using a FTS Systems, Dura-Dry ${ }^{\mathrm{TM}}$ MP freeze dryer (New York, USA). The IR spectra of the lyophilized samples were recorded using a Bruker Optics, TENSOR 27 FT-IR spectrometer (Ettlingen, Germany); over a spectral range of $400-4000 \mathrm{~cm}^{-1}$. The Raman spectrum of the synthesized nanoparticles was recorded at room temperature using the 532-nm line from a SUWTECH, G-SLM diode laser (Shanghai, China). The scattered light was collected and detected using a CCD-based monochromator, covering a spectral range of $150-1700 \mathrm{~cm}^{-1}$. The sample solution was taken in a standard $1 \mathrm{~cm} \times 1 \mathrm{~cm}$ cuvette and placed in the path of the laser beam. 


\section{Results and discussion}

\section{Synthesis of silver nanoparticles}

The present experimental investigation reports the green synthesis of silver nanoparticles using gum ghatti by autoclaving. This method utilizes a proteinaceous, edible, renewable, and water soluble biopolymer; gum ghatti which functions as both reducing and stabilizing agents during synthesis. By virtue of being a natural polymer, this gum is also amenable for biodegradation. The process of autoclaving makes the silver nanoparticles intrinsically safe and sterile, in environmentally benign solvent water. Moreover, generation of gum-silver nanoparticles by autoclaving is a prerequisite for biological applications. Thus, the adopted method is meeting the requirements of green chemistry principles.

\section{Proposed mechanism of reduction}

During autoclaving at $121^{\circ} \mathrm{C}$ under the influence of temperature and pressure $(103 \mathrm{kPa})$, this biopolymer expands and becomes more accessible for the silver ions to interact with the available functional groups on the gum as observed earlier for starch [1]. The gum has been categorized under arabinogalactan due to the abundance of arabinose and galactose. This acidic heteropolysaccharide is known to be rich in uronic acid content and shows a $\mathrm{pH}$ of 4.5-5.5 [8,14-17]. The presence of hydroxyl and carboxylic groups on this biopolymer [28] facilitates the complexation of silver ions. Subsequently, these silver ions oxidize the hydroxyl groups to carbonyl groups, during which the silver ions are reduced to elemental silver. In addition to this inherent oxidation, the dissolved air may also causes oxidation of the existing hydroxyl groups to carbonyl groups such as aldehydes and carboxylates. In turn, these powerful reducing aldehyde groups along with the other existing carbonyl groups reduce more and more of silver ions to elemental silver. Further, these nanoparticles are probably capped and stabilized by the polysaccharides along with the proteins present in the gum. As these carbohydrate polymers are very complex, it is most likely that more than one mechanism is involved in the complexation and subsequent reduction of silver ions by gum ghatti during autoclaving. Silver ion complexation by hydroxyl groups and its subsequent reduction by aldehyde groups are reported for starch, in which silver nanoparticles were produced by autoclaving [1]. Silver nanoparticles produced using gum Acacia, carboxylate groups involving complexation of silver ions and its subsequent reduction by hydroxyl groups were reported [4].

The reduction of silver ions by this gum even at room temperature was observed. But, the formed nanoparticles were not stable and aggregated due to lack of stabilization of the synthesized nanoparticles. It was noticed that the autoclaving at $121^{\circ} \mathrm{C}$ and $103 \mathrm{kPa}$ of pressure, increased the extent of synthesis and stabilization of the nanoparticles. It is known that elevated temperature and pressure accelerate the synthesis of nanoparticles [1]. Besides, this process complexly eliminates the microbial contamination possibly acquired during gum secretion, collection, handling, and transportation.

\section{Characterization of synthesized silver nanoparticles UV-Visible spectroscopy}

The UV-Vis absorption spectroscopy is one of the most widely used simple and sensitive techniques for the observation of nanoparticle synthesis. In order to monitor the formation of silver nanoparticles, the absorption spectra of synthesized silver nanoparticles were recorded against respective autoclaved gum blanks. Figure 1 is indicating (a) gum tears of grade 1 quality, (b) gum powder sieved to $38 \mu \mathrm{m}$ particle size, and (c) centrifuged gum solution of $0.5 \%$. To optimize the nanoparticle synthesis, the influence of parameters such as concentration of gum and reaction time was studied. The role of gum concentration on the synthesis was studied by autoclaving these gum solutions $(0.1-0.5 \%)$ containing $1 \mathrm{mM}$ of silver nitrate for $30 \mathrm{~min}$. Figure $2 \mathrm{a}$ shows the UV-Vis spectra of the produced silver nanoparticles with different concentrations of gum $(0.1-0.5 \%)$ at $1 \mathrm{mM} \mathrm{AgNO}_{3}$ and $30 \mathrm{~min}$ of autoclaving. After autoclaving the silver nitrate containing gum solutions, the appearance of yellow color in the reaction mixtures was observed. This is a clear indication for the formation of silver nanoparticles by the gum. It reveals that the efficiency of nanoparticle synthesis increases with increasing concentration of gum. The synthesis was also evaluated by varying the reaction time (10-60 $\mathrm{min}$ ) and reduction was studied with $0.5 \%$ gum at $1 \mathrm{mM} \mathrm{AgNO}_{3}$ (Figure 2b). It was noticed that the reduction capacity of the gum increased with reaction time. As the autoclaving time increases, possibly more and more of hydroxyl groups are being converted to carbonyl groups by air oxidation, which in turn reduce the silver ions. In the UV-Vis spectra a single strong peak with a maximum around $412 \mathrm{~nm}$ was observed, which corresponds to the typical surface plasmon resonance (SPR) of conducting electrons from the surface of silver nanoparticles. The SPR absorption of metal nanoparticles like gold and silver is very sensitive to the changes of the size and shape of the nanoparticles formed [29].

\section{Transmission electron microscopy}

Figure 3 shows the TEM images of the silver nanoparticles synthesized with $0.5 \%$ gum and $1 \mathrm{mM} \mathrm{AgNO}_{3}$ autoclaved for $30 \mathrm{~min}$. These nanoparticles are spherical, polydisperse, aggregated, and the average particle size obtained from these micrographs was about $31.6 \pm 21.7 \mathrm{~nm}$ (Figure 3c). The 

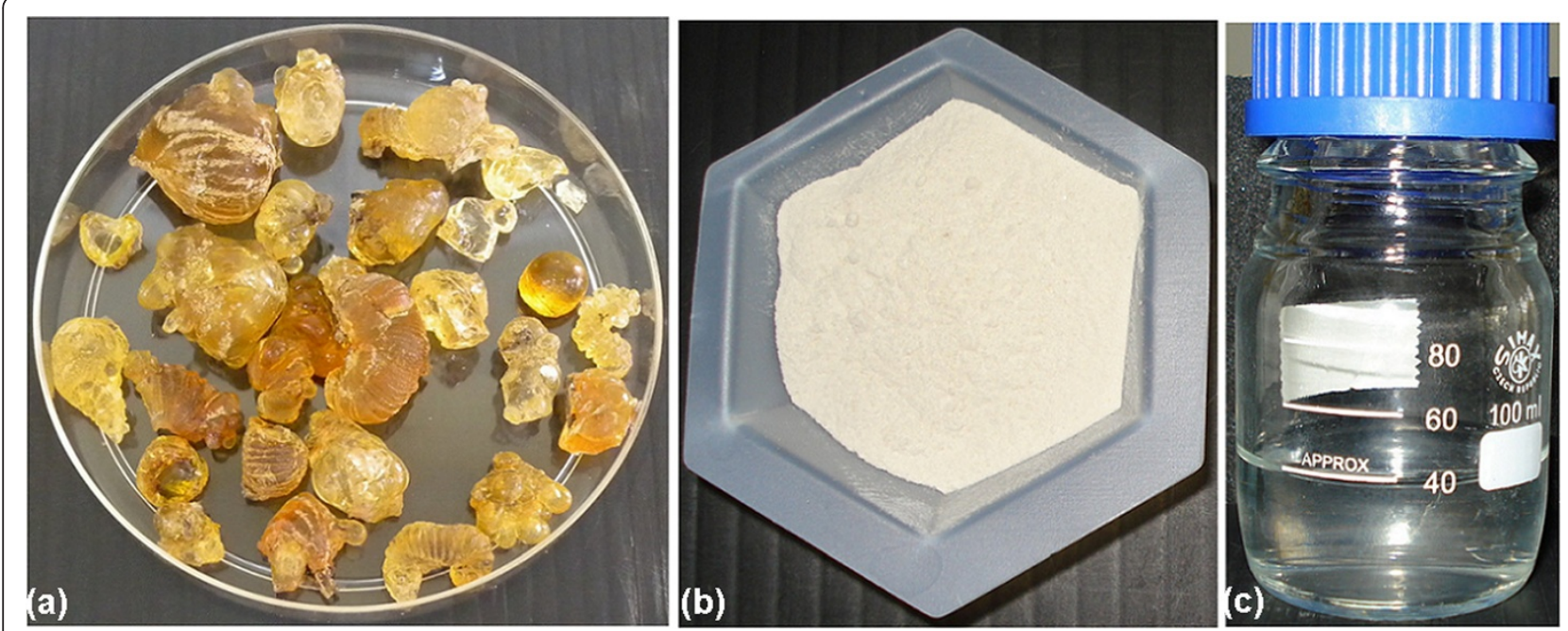

Figure 1 A digital photograph showing (a) Gum tears of grade 1 quality, (b) gum powder sieved to $38 \mu \mathrm{m}$ particle size, and (c) centrifuged gum solution of $0.5 \%(\mathrm{w} / \mathrm{v})$.

influence of gum concentration on the morphology of the nanoparticles was investigated with $0.1 \%$ gum and $1 \mathrm{mM}$ $\mathrm{AgNO}_{3}$, autoclaved for $30 \mathrm{~min}$ (Figure 4). These nanoparticles were spherical in shape and nearly isotropic in nature. The average particle size obtained from the corresponding diameter distribution was about $5.7 \pm 0.2 \mathrm{~nm}$ (Figure 4e). The effect of autoclaving time on the shape and size of the nanoparticles was confirmed with $0.1 \%$ gum solution, autoclaved for $60 \mathrm{~min}$ at $1 \mathrm{mM} \mathrm{AgNO}$ (Figure 5). The TEM observations of this sample indicate the shape anisotropy and the nanoparticles display a rich variety of shapes in varying sizes. In addition to nanospheres, hexagonal, and polygonal nanoprisms, ellipsoidal and uneven shaped nanoparticles were observed. These nanoparticles are polydisperse, aggregated, and the average particle size obtained from these micrographs was about $27.2 \pm 11.5 \mathrm{~nm}$, for $60 \mathrm{~min}$ of reaction time (Figure 5e). The selected-area electron diffraction (SAED) patterns depicted in Figures $4 \mathrm{~d}$ and $5 \mathrm{~d}$ exhibit concentric rings with intermittent bright dots, indicating that these nanoparticles are highly crystalline in nature. These rings can be attributed to the diffraction from the (111), (200), (220), and (311) planes of face-centered
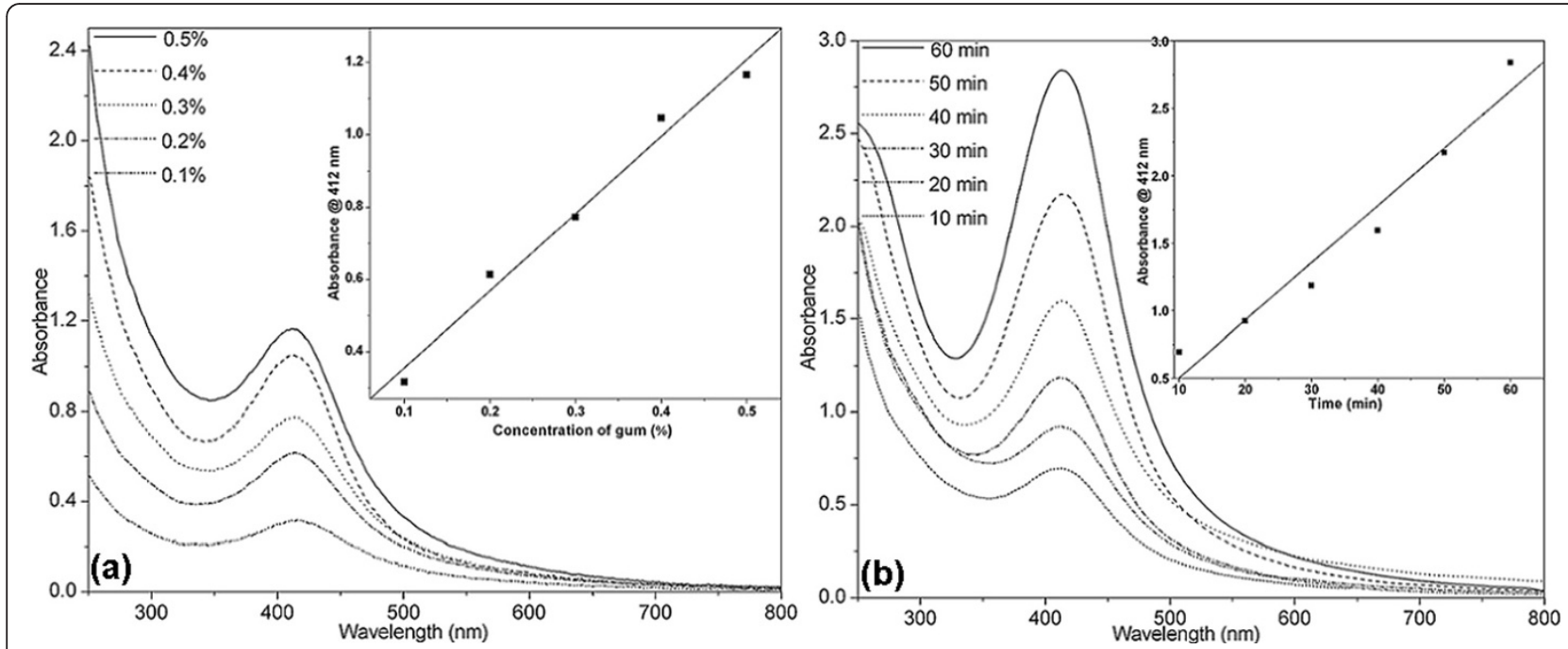

Figure 2 The UV-Vis absorption spectra of silver nanoparticles synthesized: (a) by autoclaving different concentrations of gum ghatti solutions at $1 \mathrm{mM} \mathrm{AgNO}{ }_{3}$ concentration for $30 \mathrm{~min}$; inset plot of $A_{\max }$ versus gum concentration and (b) with $0.5 \%$ (w/v) gum ghatti solutions at $1 \mathrm{mM} \mathrm{AgNO}_{3}$ concentration for different durations of autoclaving; inset plot of $A_{\text {max }}$ versus autoclaving time. 


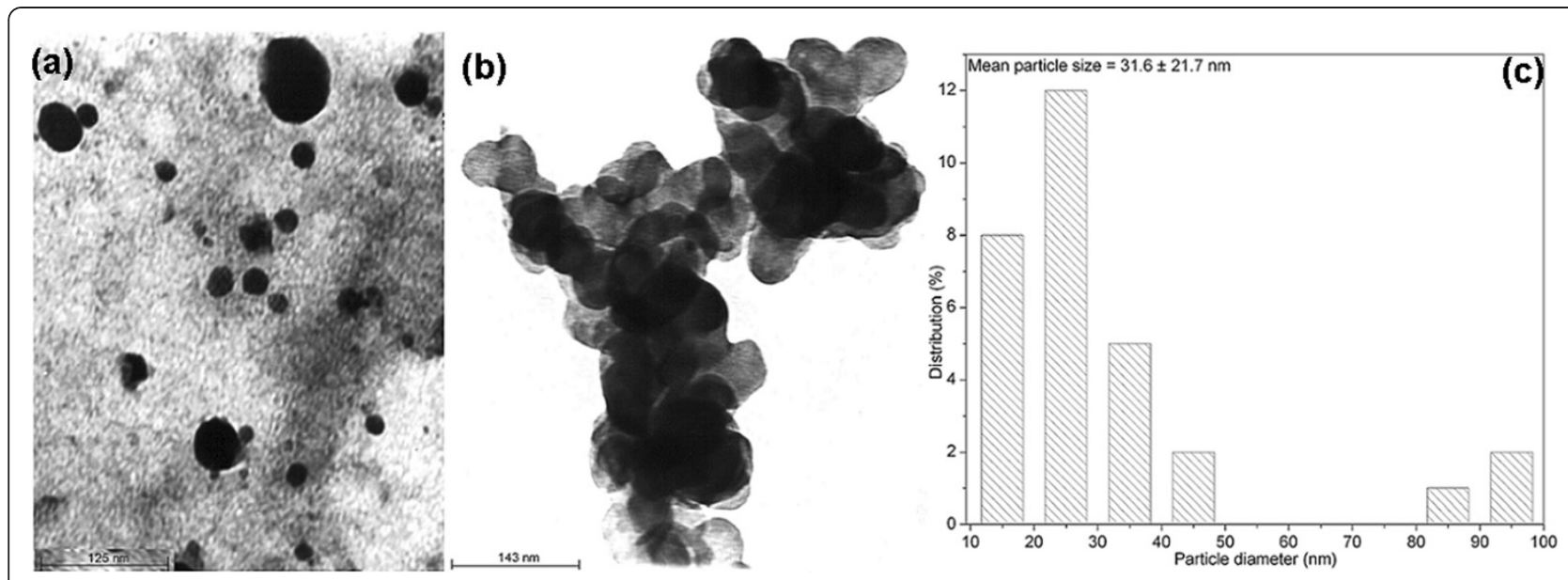

Figure 3 TEM images of silver nanoparticles synthesized with $0.5 \%(\mathrm{w} / \mathrm{v})$ gum ghatti and $1 \mathrm{mM} \mathrm{AgNO}{ }_{3}$, autoclaved for $30 \mathrm{~min}$, at (a) $125 \mathrm{~nm}$, (b) $143 \mathrm{~nm}$ scale, and (c) histogram showing the particle size distribution.

cubic (fcc) silver. The crystallinity of the synthesized nanoparticles was also supported from the observed clear lattice fringes in high-resolution images (Figures $4 \mathrm{c}$ and $5 \mathrm{c}$ ). Interestingly at $0.1 \%$ gum and $1 \mathrm{mM}$ of $\mathrm{AgNO}_{3}$ concentration with 30 min of autoclaving, nearly $70 \%$ of the nanoparticles formed were in the size of $5.7 \mathrm{~nm}$ (Figure 4e). When the concentration of gum was decreased from 0.5 to $0.1 \%$, the average particle size of the silver nanoparticles formed
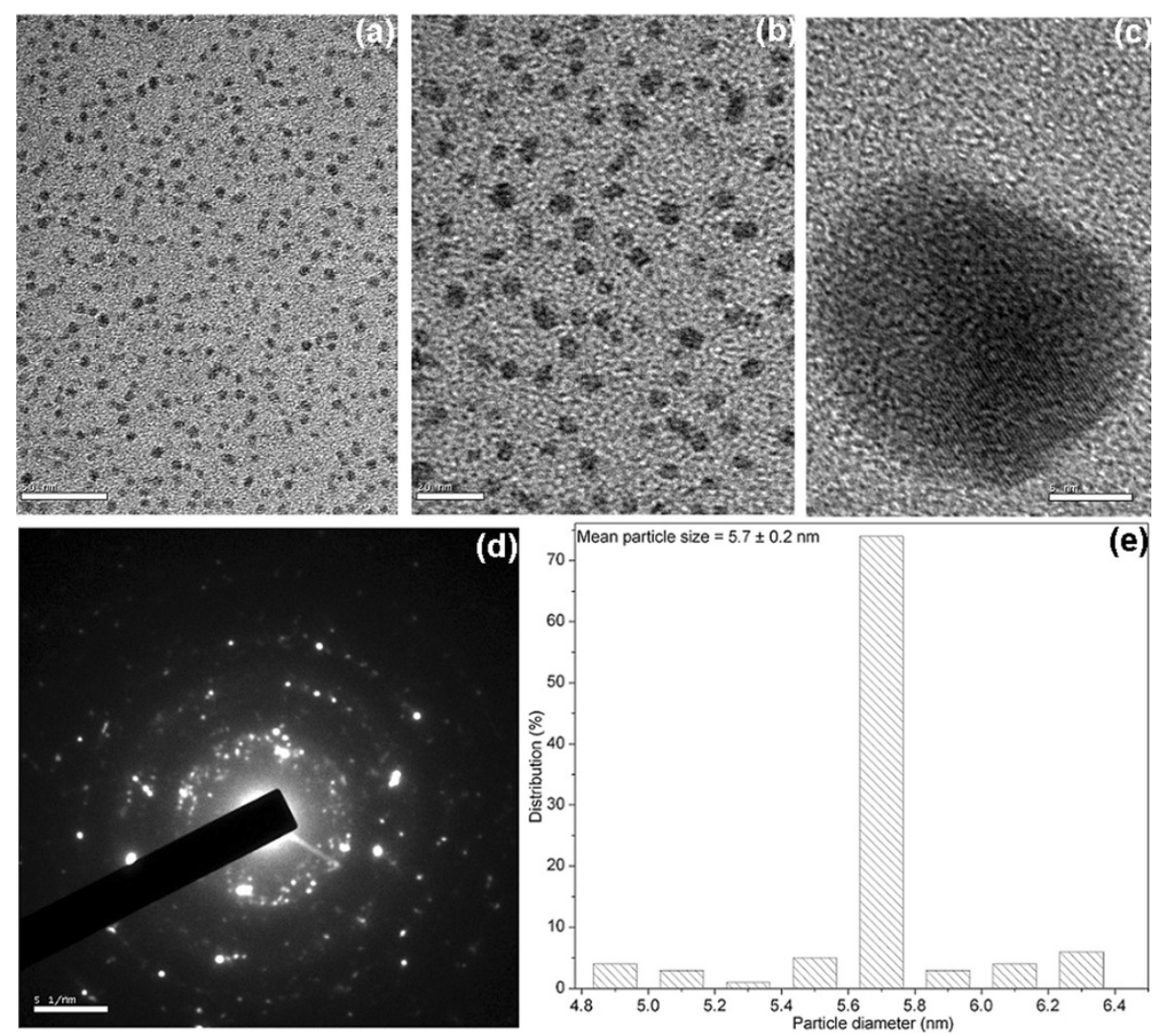

Figure 4 TEM images of silver nanoparticles synthesized with $0.1 \%(\mathrm{w} / \mathrm{v})$ gum ghatti and $1 \mathrm{mM} \mathrm{AgNO}$, autoclaved for $30 \mathrm{~min}$, at (a) $50 \mathrm{~nm}$, (b) $20 \mathrm{~nm}$, and (c) $5 \mathrm{~nm}$ scale. (d) Corresponding SAED pattern and (e) histogram showing the particle size distribution. 

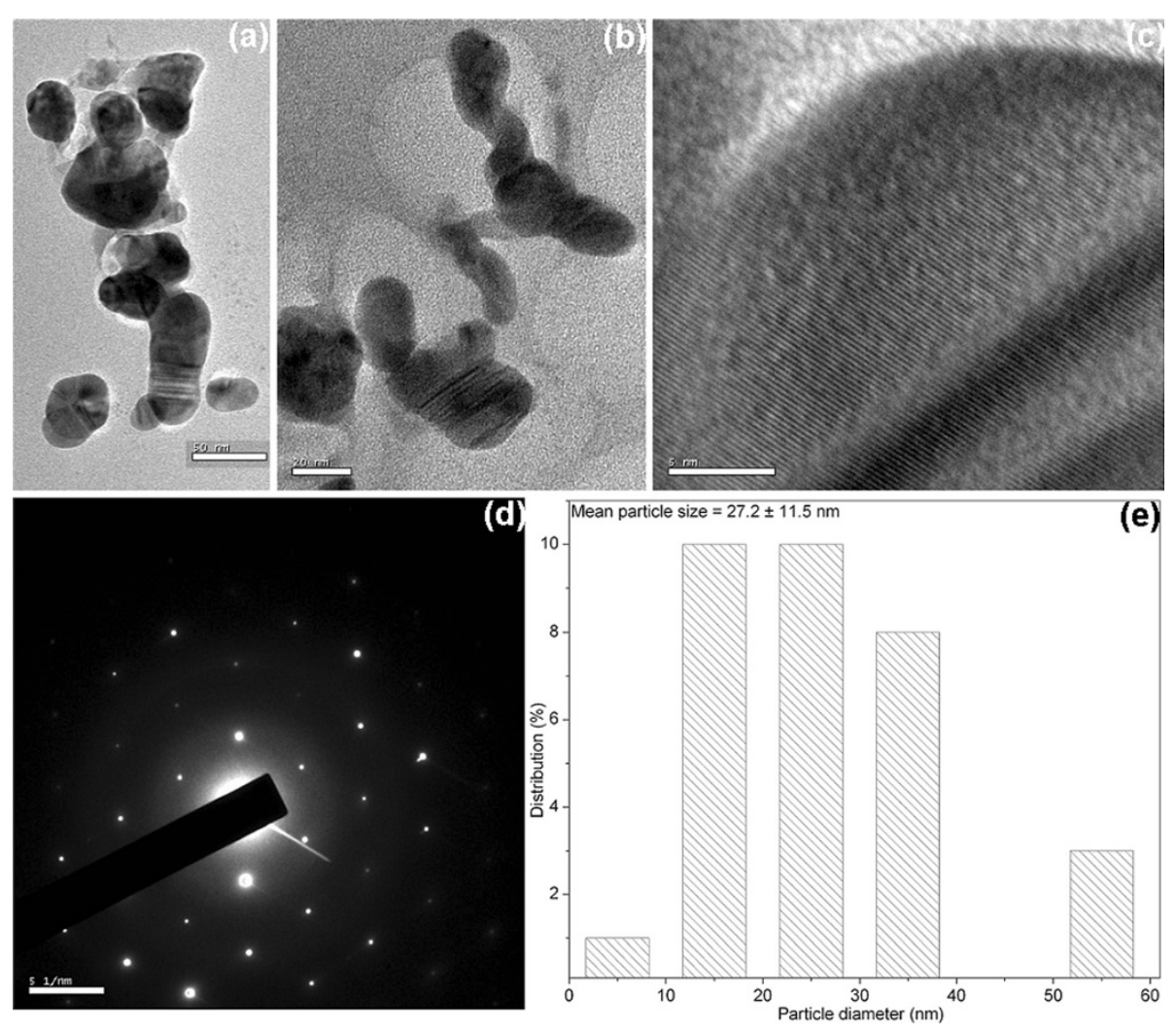

Figure 5 TEM images of silver nanoparticles synthesized with $0.1 \%(\mathrm{w} / \mathrm{v})$ gum ghatti and $1 \mathrm{mM} \mathrm{AgNO}{ }_{3}$, autoclaved for $60 \mathrm{~min}$, at (a) $50 \mathrm{~nm}$, (b) $20 \mathrm{~nm}$, and (c) $5 \mathrm{~nm}$ scale. (d) Corresponding SAED pattern and (e) histogram showing the particle size distribution.

decreased. This was also confirmed in a previous study on size controllable synthesis of silver nanoparticles with tannic acid, in which the concentration of the polyphenol decreased from 23.5 to $1.8 \mu \mathrm{M}$ [3]. The decrease in polydispersity with decrease in the concentration of gum was also evident from the TEM images (Figures 3 and 4). It is worth noting that the shape of the particles changed from spheres to anisotropic nanostructures, when the reaction time was increased to $60 \mathrm{~min}$ at $0.1 \%$ of gum concentration (Figures 4 and 5). This is most likely due to the continual growth of nanoparticles during longer period of autoclaving. This study indicates that the particle size of the silver nanoparticles can be controlled by varying the concentration of gum and reaction time. As a result, nanoparticles with near monodispersity were obtained with $0.1 \%$ gum and 30 min of reaction time at $1 \mathrm{mM}$ of silver nitrate concentration.

\section{$X$-ray diffraction}

The XRD technique was used to determine and confirm the crystal structure of silver nanoparticles. The XRD pattern of the silver nanoparticles is shown in Figure 6. There were five well-defined characteristic diffraction peaks at $38.3^{\circ}, 44.6^{\circ}, 64.8^{\circ}, 77.6^{\circ}$, and $81.9^{\circ}$, respectively, corresponding to (111), (200), (220), (311), and (222) planes of fcc crystal structure of metallic silver. The interplanar spacing $\left(d_{h k l}\right)$ values $(2.348,2.030,1.437$, 1.229, and $1.175 \AA$ ) calculated from the XRD spectrum of silver nanoparticles was in agreement with the standard silver values. Thus, the XRD pattern further corroborates the highly crystalline nature of nanoparticles observed from SAED patterns and high-resolution TEM images (Figures 4 and 5). The lattice constant calculated from this pattern was $4.061 \AA$, a value which is in agreement with the value reported in literature for silver (JCPDS PDF card 04-0783). Also, the broadening of the diffraction peaks was observed owing to the effect of nano-sized particles. As the nanoparticles are capped by the moieties of gum, the background observed was high.

\section{Fourier transform infrared spectroscopy (FTIR)}

The FTIR spectra of the gum and nanoparticles were recorded in order to identify the functional groups of gum involved in the reduction and capping/stabilization of the synthesized nanoparticles. Figure 7 shows the FTIR spectra of the lyophilized gum and silver nanoparticles. The major absorbance bands present in the 


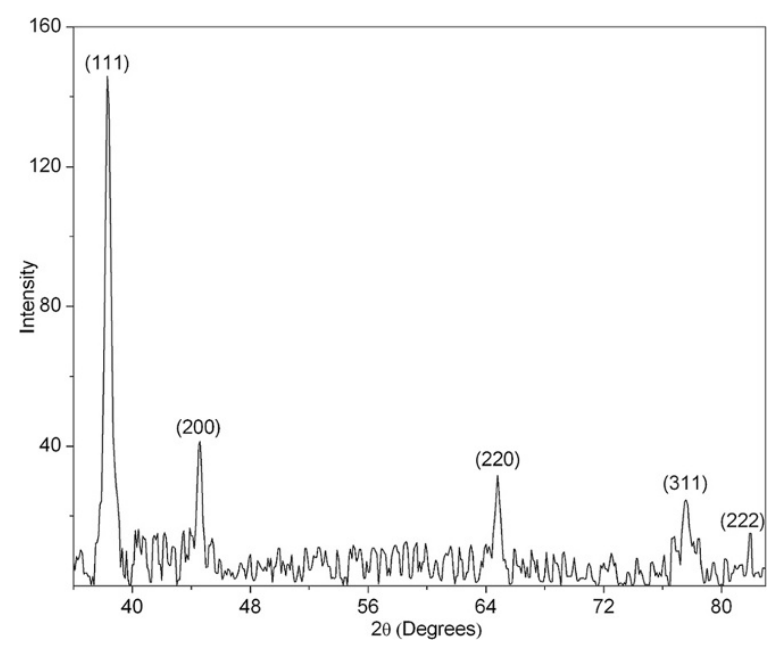

Figure 6 XRD pattern of the silver nanoparticles, indicating fcc crystal structure.

spectrum of gum ghatti were at $3425,2928,2368,2341$, $2122,1635,1406,1311,1234,1068$, and $1028 \mathrm{~cm}^{-1}$. The broad band observed at $3425 \mathrm{~cm}^{-1}$ could be assigned to stretching vibrations of $\mathrm{O}-\mathrm{H}$ groups in gum ghatti. The bands at 2928,1406 , and $1234 \mathrm{~cm}^{-1}$ correspond to asymmetric stretching, scissoring; and twisting and rocking vibrations of methylene groups, respectively. The broad band at $2122 \mathrm{~cm}^{-1}$ only appeared in the spectrum of gum could be assigned to various carbonyl species. The stronger band found at $1635 \mathrm{~cm}^{-1}$ could be assigned to characteristic asymmetrical stretch of carboxylate group. The symmetrical stretch of carboxylate group can be attributed to the band present at $1311 \mathrm{~cm}^{-1}$. The peaks at 1068 and $1028 \mathrm{~cm}^{-1}$ were due to the $\mathrm{C}-\mathrm{O}$ stretching vibration of ether and alcoholic groups, respectively [28]. While, the spectrum of lyophilized nanoparticles showed characteristic absorbance bands at 3431, 2964, 2345, 2304, $1728,1632,1385,1260$, and $1024 \mathrm{~cm}^{-1}$. In the IR spectrum of nanoparticles, a shift in the absorbance peaks was observed from 3425 to $3431 \mathrm{~cm}^{-1}$ and 1635 to $1632 \mathrm{~cm}^{-1}$, and 1311 to $1385 \mathrm{~cm}^{-1}$, suggesting the binding of silver ions with hydroxyl and carboxylate groups, respectively. It is pertinent to note that nanoparticles shows a new band at $1728 \mathrm{~cm}^{-1}$ corresponding to carbonyl stretching vibrations in aldehydes, ketones, and carboxylic acids [2]. Further, the occurrence of the peak at $1728 \mathrm{~cm}^{-1}$ and disappearance of the peak at $2122 \mathrm{~cm}^{-1}$ confirm that the reduction of the silver ions is coupled to the oxidation of the hydroxyl and carbonyl groups, indicative of more extensively oxidized nature of the gum. Based on the band shift in the hydroxyl and carbonyl groups and the loss of existing carbonyls and appearance of a new carbonyl peak, it can be inferred that both hydroxyl and carbonyl groups of gum are involved in the synthesis of silver nanoparticles. The variations in the shape and peak position of the hydroxyl and carboxylate groups have been reported, where silver nanoparticles were synthesized using another polysaccharide, gum Acacia [4].

\section{Raman spectroscopy}

In order to find out the possible functional groups of capping agents associated in the stabilization of silver nanoparticles, Raman spectrum of the nanoparticles was recorded. Figure 8 gives the selective enhancement of Raman bands of the organic capping agents bound to the nanoparticles. The spectrum shows a strong and sharp band at $240 \mathrm{~cm}^{-1}$, which can be attributed to the stretching vibrations of $\mathrm{Ag}-\mathrm{N}[30,31]$ and $\mathrm{Ag}-\mathrm{O}$ bonds [32]. This

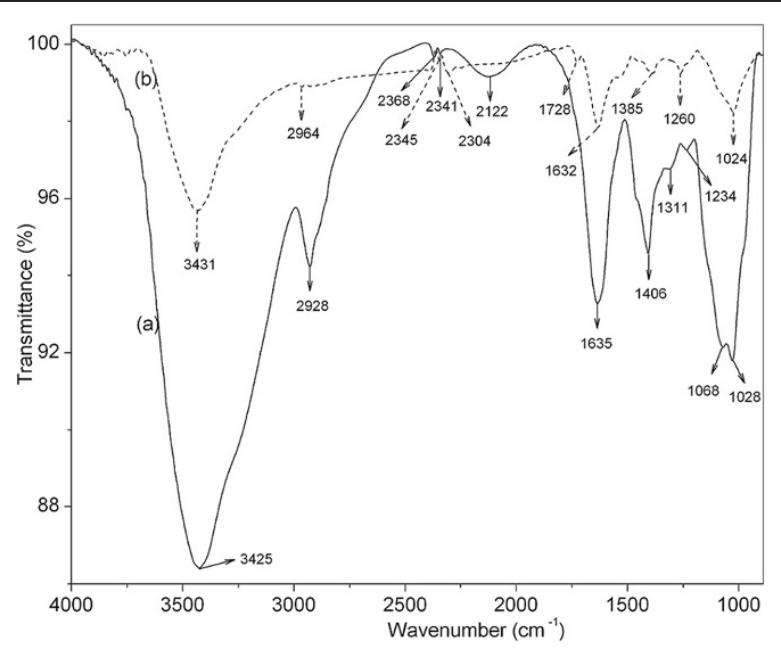

Figure 7 FTIR spectra of freeze dried (a) gum ghatti and (b) silver nanoparticles. 


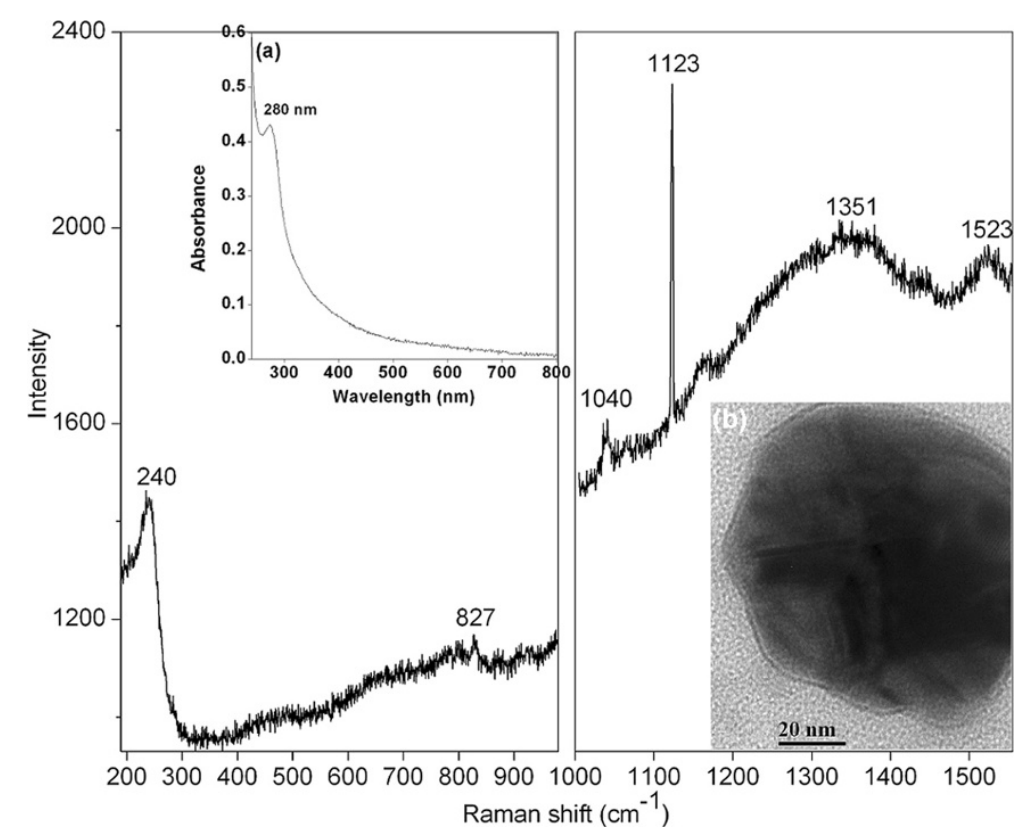

Figure 8 Raman spectrum of aqueous silver nanoparticle solution. (a) UV-Vis absorption spectrum of the $0.5 \%$ (w/v) gum solution against water blank, autoclaved for $30 \mathrm{~min}$ and (b) TEM image of a single nanoparticle, surrounded by a layer of organic matrix.

peak indicates the formation of a chemical bond between silver and amino nitrogen [31]; and silver and carboxylate groups [32] of gum molecules. It confirms that the gum is bound to the silver nanoparticle surface either through amino or carboxylate group or both. It is known to have close frequencies for the $\mathrm{Ag}-\mathrm{N}$ and $\mathrm{Ag}-\mathrm{O}$ stretching vibrations and the involvement of both $\mathrm{N}$ and $\mathrm{O}$ atoms in binding result in surface-enhanced Raman scattering (SERS) band broadening [30]. The broad ones at 1351 and $1523 \mathrm{~cm}^{-1}$ correspond to symmetric and asymmetric $\mathrm{C}=\mathrm{O}$ stretching vibrations of carboxylate group, respectively [31]. The enhancement in the intensity of the $\mathrm{CO}_{2}$ stretching vibration suggests the direct binding of the $\mathrm{COO}^{-}$group with the silver surface [32]. The broad band at 1040 and a sharp peak at $1123 \mathrm{~cm}^{-1}$; the one at $827 \mathrm{~cm}^{-1}$ comes from the $\mathrm{C}-\mathrm{H}$ in plane bending and out of plane wag, respectively [30], from the saccharide structure of gum. Thus, from the preferential enhancement of these bands; it can be concluded that both amino and carboxylate groups of the gum are involved in the capping of the silver nanoparticles. These results are in concurrence with earlier biosynthesis of silver nanoparticles carried out with non-pathogenic fungus Trichoderma asperellum [31]. It was reported earlier that the carboxylate groups of glycoprotein of gum Acacia were involved in binding of silver nanoparticles [4]. It is known that proteins can bind to nanoparticles either through free amino groups or by electrostatic interaction of negatively charged carboxylate groups [33]. The gum ghatti is known to contain protein and the protein content was reported to be in the range of $2.8-3.7 \%$ [13-17]. This observation is further substantiated by the measured protein concentration of $2.7 \%$ for the gum and the UV-Vis absorption spectrum of the $0.5 \%$ gum solution against water blank, autoclaved for $30 \mathrm{~min}$, given in Figure 8a. An absorption peak at $280 \mathrm{~nm}$ is clearly visible and is attributed to electronic excitations in tryptophan and tyrosine residues in the proteins $[1,33]$, which are present in the gum. The stabilization of nanoparticles by capping agents is also validated from the TEM image showing a single nanoparticle that is surrounded by a layer of organic matrix (Figure 8b). Thus, one can conclude that once the silver ions are reduced to silver nanoparticles by the polyhydroxylated gum, proteins present in the gum subsequently encapsulate and stabilize these particles along with saccharide molecules. Based on these observations, these silver nanoparticles can be used as a possible substrate for SERS. As observed in IR spectra (Figure 7), gum ghatti is rich in various functional groups; and their capping on silver nanoparticles provides surface reactivity. It is reported that the functional unit used as a capping agent plays an important role and determines the tissue distribution profile of gold nanoparticles [34]. Thus, these functionalized nanoparticles are useful for various applications such as drug delivery [6], targeted biological interactions [34], and biological labels [35].

\section{Antibacterial assay}

For checking the antibacterial activity, silver nanoparticles with an average size of $5.7 \pm 0.2 \mathrm{~nm}$ were used. These nanoparticles were prepared with $0.1 \%$ gum solution containing 
$1 \mathrm{mM} \mathrm{AgNO}$, autoclaved for $30 \mathrm{~min}$. After $24 \mathrm{~h}$ of incubation at $37^{\circ} \mathrm{C}$, growth suppression was observed in plates loaded with $5 \mu \mathrm{g}$ of silver nanoparticles. Whereas, the negative control plates loaded with autoclaved gum did not produce any ZOI. Gum-silver nanoparticles showed growth inhibition around the wells against the tested bacteria. ZOI of around $12.25 \mathrm{~mm}$ diameter was observed for the Grampositive bacterial strain S. aureus ATCC 25923. In the case of Gram-negative bacterial strains E. coli ATCC 25922, E. coli ATCC 35218, and P. aeruginosa ATCC 27853, the detected ZOI were 9.0, 8.0, and $11.0 \mathrm{~mm}$, respectively. As expected, the positive control plates loaded with silver nitrate exhibited inhibition zones (Table 1). The ZOI values noted for different bacterial strains with silver nanoparticles are comparable with the positive controls. Based on these results, it can be concluded that the synthesized silver nanoparticles had significant antibacterial action on both the Gram classes of bacteria.

\section{Experimental}

Synthesis of silver nanoparticles

Silver nitrate $\left(\mathrm{AgNO}_{3}\right)$ (E. Merck, Mumbai, India) of analytical reagent grade was used for the synthesis. "Gum ghatti" grade-1 was purchased from Girijan Cooperative Corporation Ltd., Hyderabad, India. All the solutions were prepared in ultra pure water. Gum ghatti was powdered in a Prestige high-speed mechanical blender (Bengaluru, India) and sieved to obtain a mean particle size of $38 \mu \mathrm{m}$. Then, $0.5 \%(\mathrm{w} / \mathrm{v})$ of homogenous gum stock solution was prepared by adding this powder to reagent bottle containing ultra pure water and stirring overnight at room temperature. Then this solution was centrifuged to remove the insoluble materials and the supernatant was used for all the experiments. The protein concentration in the gum solution was quantified by Lowry's method using a Bangalore Genei ${ }^{\mathrm{TM}}$ protein estimation kit, Cat No 105560 (Bengaluru, India). The silver nanoparticles were synthesized by autoclaving the silver nitrate solutions containing various concentrations of gum ghatti at $121^{\circ} \mathrm{C}$ and $103 \mathrm{kPa}$ of pressure for different durations of time, under dark conditions. The effect of concentration of gum and reaction time on nanoparticle synthesis was studied.

\section{Antibacterial assay}

The well-diffusion method was used to study the antibacterial activity of the synthesized silver nanoparticles.
All the glassware, media, and reagents used were sterilized in an autoclave at $121^{\circ} \mathrm{C}, 103 \mathrm{kPa}$ of pressure for 20 min. Staphylococcus aureus (ATCC 25923); and Escherichia coli (ATCC 25922), E. coli (ATCC 35218), and Pseudomonas aeruginosa (ATCC 27853) were used as model test strains for Gram-positive and Gramnegative bacteria, respectively. Bacterial suspension was prepared by growing a single colony overnight in nutrient broth and by adjusting the turbidity to 0.5 McFarland standard [36]. Mueller Hinton agar plates were inoculated with this bacterial suspension and $5 \mu \mathrm{g}$ of silver nanoparticles was added to the center well with a diameter of $6 \mathrm{~mm}$. The nanoparticles used were prepared with $0.1 \%$ gum solution containing $1 \mathrm{mM} \mathrm{AgNO}_{3}$, autoclaved for $30 \mathrm{~min}$. Negative control plates were maintained with autoclaved gum-loaded wells. The culture plates loaded with silver nitrate at a silver concentration of $5 \mu \mathrm{g}$ were included as positive controls. These plates were incubated at $37^{\circ} \mathrm{C}$ for $24 \mathrm{~h}$ in a bacteriological incubator and the zone of inhibition (ZOI) was measured by subtracting the well diameter from the total inhibition zone diameter. Three independent experiments were carried out with each bacterial strain.

\section{Conclusions}

This study reports the facile synthesis of silver nanoparticles from silver nitrate using gum ghatti. The adopted method is compatible with green chemistry principles as the gum serves as a dual functional reductant and stabilizer for the synthesis of nanoparticles. At a given gum concentration, the efficiency of nanoparticle synthesis increases with reaction time, a property attributable to the large reduction capacity of the gum. As the particle size of the nanoparticles can be controlled, this method can be implemented for the large-scale production of monodispersed and spherical nanoparticles of around $5.7 \mathrm{~nm}$ due to the availability of low-cost plantderived biopolymer. The hydroxyl and carboxylate groups of the gum facilitate the complexation of silver ions during autoclaving. Subsequently, these silver ions are reduced to elemental silver possibly by in situ oxidation of hydroxyl groups; and by the intrinsic carbonyl groups in addition to those produced by the air oxidation. This proposed mechanism is also substantiated by the FTIR data. Further, the formed silver nanoparticles had significant antibacterial action on both the Gram classes of bacteria. The surface reactivity provided by

Table 1 Inhibition zones $(\mathrm{mm})$ observed with different bacterial culture plates loaded with silver nanoparticles and silver nitrate at a silver concentration of 5 $\mathbf{~ g}$

\begin{tabular}{|c|c|c|c|c|}
\hline Test compound & S. aureus 25923 & E. coli 25922 & E. coli 35218 & P. aeruginosa 27853 \\
\hline Silver nanoparticles & 12.25 & 9.0 & 8.0 & 11.0 \\
\hline Silver nitrate & 13.5 & 11.0 & 7.6 & 12.0 \\
\hline
\end{tabular}


capping enables these functionalized nanoparticles as promising candidates for various pharmaceutical, biomedical, and environmental applications. Notably, the selective enhancement of Raman bands of the organic capping agents bound to the silver colloids allows these nanoparticles as suitable substrates for SERS. In view of this, further studies are envisaged to explore the other potential applications of this gum-based nanoparticles.

\section{Competing interests}

The authors declare that they have no competing interests.

\section{Acknowledgments}

We thank Dr. S. V. Narasimhan, Associate Director and Dr. Tulsi Mukherjee, Director, Chemistry Group, BARC, for their constant support and encouragement for this study. The support rendered for high-resolution TEM measurements by the DST unit on Nanoscience, Sophisticated Analytical Instrument Facility (SAIF) at IIT-Madras, Chennai, is gratefully acknowledged.

\section{Author details}

${ }^{1}$ National Centre for Compositional Characterisation of Materials (NCCCM), Bhabha Atomic Research Centre, ECIL PO, Hyderabad 500 062AP, India. ${ }^{2}$ Department of Biochemistry, University College of Science, Osmania University, Hyderabad 500 007, AP, India.

\section{Received: 17 October 2011 Accepted: 9 May 2012}

\section{Published: 9 May 2012}

\section{References}

1. Vigneshwaran N, Nachane RP, Balasubramanya RH, Varadarajan PV (2006) A novel one-pot 'green' synthesis of stable silver nanoparticles using soluble starch. Carbohydr Res 341:2012-2018

2. Wei D, Qian W (2008) Facile synthesis of Ag and Au nanoparticles utilizing chitosan as a mediator agent. Colloids Surf B 62:136-142

3. Dadosh T (2009) Synthesis of uniform silver nanoparticles with a controllable size. Mater Lett 63:2236-2238

4. Mohan YM, Raju KM, Sambasivudu K, Singh S, Sreedhar B (2007) Preparation of acacia-stabilized silver nanoparticles: a green approach. J Appl Polym Sci 106:3375-3381

5. Kora AJ, Sashidhar RB, Arunachalam J (2010) Gum kondagogu (Cochlospermum gossypium): a template for the green synthesis and stabilization of silver nanoparticles with antibacterial application. Carbohydr Polym 82:670-679

6. Dhar S, Reddy EM, Shiras A, Pokharkar V, Prasad BLV (2008) Natural gum reduced/stabilized gold nanoparticles for drug delivery formulations. Chem Eur J 14:10244-10250

7. Panda H (2003) Gum ghatti. In: The complete technology book on natural products (Forest based). National Institute of Industrial Research, Delhi, pp $1-9$

8. Nussinovitch A (2010) Miscellaneous uses of plant exudates. In: Plant gum exudates of the world: sources, distribution, properties and applications. CRC Press, Taylor and Francis, Boca Raton, USA, pp 347-368

9. Srivastava VK, Rai RS (1963) Physico-chemical studies on gum Dhawa (Anogeissus latifolia wall.). Colloid Polym Sci 190:140-143

10. Aspinall GO, Bhavanadan VP, Christensen TB (1965) Gum ghatti (Indian gum). Part V. Degradation of the periodate-oxidised gum. J Chem Soc 2677-2684

11. Jefferies M, Pass G, Phillips GO (1977) Viscosity of aqueous solutions of gum ghatti. J Sci Food Agric 28:173-179

12. Tischer CA, lacomini M, Wagner R, Gorin PAJ (2002) New structural features of the polysaccharide from gum ghatti (Anogeissus latifola). Carbohydr Res 337:2205-2210

13. Amar V, Al-Assaf S, Phillips GO (2006) An introduction to gum ghatti: another proteinaceous gum. Foods Food Ingredients J Jpn 211:275-280

14. Katayama T, Ido T, Sasaki Y, Ogasawara T, Al-Assaf S, Phillips GO (2008) Characteristics of the adsorbed component of gum ghatti responsible for its oil-water interface advantages. Foods Food Ingredients J Jpn 213:372-376
15. Ido T, Ogasawara T, Katayama T, Sasaki Y, Al-Assaf S, Phillips GO (2008) Emulsification properties of GATIFOLIA (Gum ghatti) used for emulsions in food products. Foods Food Ingredients J Jpn 213:365-371

16. Kaur L, Singh J, Singh H (2009) Characterization of gum ghatti (Anogeissus latifolia): a structural and rheological approach. J Food Sci 74:E328-E332

17. Castellani O, Gaillard C, Vié V, Al-Assaf S, Axelos M, Phillips GO, Anton M (2010) Hydrocolloids with emulsifying capacity. Part 3: adsorption and structural properties at the air-water surface. Food Hydrocolloids 24:131-141

18. Shahane J (2006) Dinkache ladu-remembrance of things past. http:// thecookscottagetypepad.com/curry/2006/03/dinkache_ladure.html. Accessed 17 March 2010

19. Meena KL, Yadav BL (2010) Some ethnomedicinal plants of southern Rajasthan. Indian J Tradit Knowl 9:169-172

20. Crociani F, Alessandrini A, Mucci MM, Biavati B (1994) Degradation of complex carbohydrates by Bifidobacterium spp. Int J Food Microbiol 24:199-210

21. Hill MJ (1995) Bacterial fermentation of complex carbohydrate in the human colon. Eur J Cancer Prevent 4:353-358

22. Ramberg J, Gardiner T (2002) Ghatti gum-Anogeissus latifolis stem gum (ghatti gum). GlycoEssential 7 Ingredients. http://www.glyconutrients-center. org/ghatti-gum.php. Accessed 17 March 2010

23. Mishra A, Raikwar A (2005) Anogeissus latifolia (ghatti gum): the edible gum. Vaniki Sandesh 29:27-28

24. Fahrenbach MJ, Riccardi BA, Grant WC (1966) Hypocholesterolemic activity of mucilaginous polysaccharides in white leghorn cockerels. Proc Soc Exp Biol Med 123:321-326

25. Parvathi KMM, Ramesh CK, Krishna V, Paramesha M, Kuppast IJ (2009) Hypolipidemic activity of gum ghatti of Anogeissus latifolia. Phcog Mag 5:11-14

26. Joshi MG, Setty CM, Deshmukh AS, Bhatt YA (2010) Gum ghatti: a new release modifier for zero-order release in 3-layered tablets of diltiazem hydrochloride. Indian J Pharm Educ Res 44:78-85

27. Raveendran P, Fu J, Wallen SL (2003) Completely "green" synthesis and stabilization of metal nanoparticles. J Am Chem Soc 125:13940-13941

28. Edwards HGM, Falk MJ, Sibley MG, Alvarez-Benedi J, Rull F (1998) FT-Raman spectroscopy of gums of technological significance. Spectrochim Acta A 54:903-920

29. Huanga NM, Lim HN, Radiman S, Khiew PS, Chiu WS, Hashim R, Chia CH (2010) Sucrose ester micellar-mediated synthesis of Ag nanoparticles and the antibacterial properties. Colloids Surf A 353:69-76

30. Chowdhury J, Ghosh M (2004) Concentration-dependent surface-enhanced Raman scattering of 2-benzoylpyridine adsorbed on colloidal silver particles. J Colloid Interface Sci 277:121-127

31. Mukherjee P, Roy M, Mandal BP, Dey GK, Mukherjee PK, Ghatak J, Tyagi AK, Kale SP (2008) Green synthesis of highly stabilized nanocrystalline silver particles by a non-pathogenic and agriculturally important fungus $T$. asperellum. Nanotechnology 19:075103-075109

32. Biswas N, Kapoor S, Mahal HS, Mukherjee T (2007) Adsorption of CGA on colloidal silver particles: DFT and SERS study. Chem Phys Lett 444:338-345

33. Vigneshwaran N, Ashtaputre NM, Varadarajan PV, Nachane RP, Paralikar KM, Balasubramanya RH (2007) Biological synthesis of silver nanoparticles using the fungus Aspergillus flavus. Mater Lett 61:1413-1418

34. Genevieve MF, Stan WC, Dae Young K, Raghuraman K, Kavita K, Nripen C, Kattesh K (2009) Biodistribution of maltose and gum arabic hybrid gold nanoparticles after intravenous injection in juvenile swine. Nanomed: Nanotech Biol Med 5:128-135

35. Schrand AM, Braydich-Stolle LK, Schlager JJ, Dai L, Hussain SM (2008) Can silver nanoparticles be useful as potential biological labels? Nanotechnology 19:235104-235116

36. Kora AJ, Manjusha R, Arunachalam J (2009) Superior bactericidal activity of SDS capped silver nanoparticles: Synthesis and characterization. Mater Sci Eng C 29:2104-2109

doi:10.1186/2191-2858-2-17

Cite this article as: Kora et al: Size-controlled green synthesis of silver nanoparticles mediated by gum ghatti (Anogeissus latifolia) and its biological activity. Organic and Medicinal Chemistry Letters 2012 2:17. 